\title{
REFRANES CANTADOS Y CANTARES PROVERBIALIZADOS
}

"Interviene, por último, en la formación de los proverbios un sentimiento lírico, innato en el espíritu popular y que hace que todos prefieran hablar en verso y no en prosa. El aire de canción de algunos proverbios (y esto ya es sabido) es la única explicación de su existencia"'. Menos sabido es que muchos proverbios no sólo tienen aire de canción, sino que son o han sido canciones, y que entre el mundo del refranero y el de la lírica musical hay como una zona intermedia en que ambos se encuentran, se mezclan, se funden y confunden. Explorar esa pequeña y casi incógnita tierra de los refranes-cantares y de los cantares-refranes es el objeto de esta nota, que se limita a los siglos Xv a xvn.

Que ya desde la Edad Media existía una estrecha relación entre lírica y refranero lo muestra, por ejemplo, el hecho de que la palabra refrán (como el francés refrain) significara, entre varias otras cosas, 'estribillo de una composición poética', y de que a su vez el término verso (o vieso) se aplicara en ocasiones al proverbio². Sin embargo, sólo al finalizar la Edad Media comienzan a aparecer pruebas palpables del contacto efectivo entre refranes y cantares.

\section{I}

Por lo pronto, consta que ciertos refranes solían c a $\mathrm{n}$ t a $\mathrm{r}$ s e. Hay en el Cancionero de Herberay (ca. 1463) un juego de letras en que, siguiendo un esquema fijo, cada jugador debía relatar un viaje usando palabras que comenzaran con determinada letra y acabando invariablemente con un proverbio" : "diga el

1 Alfonso Reyes, "De los proverbios y sentencias vulgares", en sus Obras completas, t. 1, México, 1955, p. 169 .

2 Véase el revelador estudio de Eleanor S. O'Kane, "On the names of the refrán", $H R, 18$ (1950), 1-14.-Dentro de la literatura culta el parentesco entre ambos géneros se refleja en la poesía gnómica de los siglos xıv y xv (don Juan Manuel, Santob de Carrión; Santillana, Pérez de Guzmán, Gómez Manrique); más tarde, en el uso de refranes como estribillos de poesías. Cf. P. Henríquez UREÑA, La versificación española irregular, $2^{a}$ ed., Madrid, 1933, pp. 92-93.

3 Le chansonnier espagnol d'Herberay des Essarts, ed. Ch. V. Aubrun, Bordeaux, 1951, pp. 188-196. En forma análoga se juega el juego en Los malcasados de Valencia de Guillén de Castro. 
refrán que se sigue...", "aqueste refrán dirá..." son las fórmulas introductorias; pero de pronto, en la letra $F$ : "este refrán le cantaron..."; en la G: "sospirando le cantauan: / "gran mal tiene / quien amores atiende»"; en la $N$ : "y este refrán le cantat..."; en la $P$ : "el refrán es de cantar...". Todos son, evidentemente, refranes en el sentido actual de la palabra ${ }^{4}$. No queda excluida la posibilidad de que al verbo cantar se le diera aquí un sentido vago, equivalente al dezir de las otras estrofas (cf. infra, nota 23). Como testimonio único, el Juego no bastaría; pero creo que las pruebas citadas a continuación demuestran que esos refranes sí se cantaban, aunque no sabemos si con una música tradicionalmente suya o con melodía improvisada para el propósito.

El siguiente paso es encontrar un refrán con su música. Nos lo ofrece, ya a fines del siglo xv, el Cancionero musical de la Colombina, en cuyo fol. $72 \mathrm{~V}^{\circ}$ aparece, arreglado para tres voces, el de Niña y viña, peral y habar, / malo es de guardar. Refrán con todas las de ley, registrado en varios refraneros antiguos ${ }^{5}$, lo mismo en esa forma (N $83 \mathrm{r}^{\circ}$ y $128 \mathrm{v}^{\circ}$, C $339 a$ y $508 a$, Ou 202 y 321 ) que en otras análogas ${ }^{6}$.

4 "Fasta que falles buen viento / nunca fagas mudamiento", "Ni por mucho madrugar / no amaneçe más aýna", "Porfía mata venado, / que no montero cansado". No sé cómo don Emilio Cotarelo ("Semántica española: refrán", $B R A E, 4,1917$, pp. 254-255) pudo decir del citado refrán de la letra G y del de la $S$ ("Si la locura fuesse dolores / en cada casa darían vozes") que "ninguno de estos dos estribillos es refrán. Más parecen pies para glosar o letras para otros juegos cortesanos". Quería mostrar Cotarelo que todavía en la segunda mitad del siglo xv refrán seguía usándose en Navarra con el sentido de 'estribillo'. Pero el hecho es que esos dos son proverbios y, por si fuera poco, que las reglas del juego exigían que se terminara precisamente con un refrán.

5 Empleo las siguientes siglas: A (= Fernando Arceo Beneventano, Adagios y fábulas [1533], ed, facs. y trad. del latín, Barcelona, 1950); C (= Gonzalo Correas, Vocabulario de refranes y frases proverbiales..., Madrid, 1924); CH (= Sebastián de Covarrubias Horozco, Tesoro de la lengua castellana o española [1611], ed. M. de Riquer, Barcelona, 1943); G (= Cartas de refranes de BLAsCo DE Garay, en Processo de cartas de amores. . . Venetia, 1553 , fols. $\left.60 \mathrm{v}^{\circ}-95 \mathrm{r}^{\circ}\right)$; H (= "Refranes glosados de Sebastín de Horozco", ed. parcial de E. Cotarelo, $B R A E, 2,1915$, 646-706; 3, 1916, 98-132, 399-428, 591-604, 710-721; 4, 1917, 383396; remito al número del refrán); $M$ (=La Silva curiosa de Ivlian de Medrano [en realidad Julio Íñguez de Medrano], cavallero navarro... [1589], nueua edicion... por Cesar Ovdin, Paris, 1608); ML (=La philosophia vulgar de IOAN DE Mallara, Sevilla, ${ }_{15} 68$ ); N (=Refranes o proverbios en romance, que nvevamente colligio y glosso el Comendador HernaN NuñEz, Salamanca, 1555); Ou (=Refranes o proverbios castellanos, traduzidos en lengua francesa... par CESAR Ovdin, [1605], Paris, 1659); S (= MarquÉs de Santillana [?], Refranes que dizen las viejas tras el fuego, ed. U. Cronan, RHi, 25, 1911, 134-219; hago referencia al número del refrán); V (=[Mosén Pedro Vallés], Libro de refranes copilado por el orden del A.B.C., Zaragoza, 1549; doy la foliación que aparece escrita a lápiz y semiborrada en el ejemplar de la H.S.A.).

6 "Mujer hermosa, viña, huerta y higueral muy malos son de guardar", M 24 (parecido en $\mathrm{N}_{7}^{8} \mathrm{v}^{0}, \mathrm{C}_{3}^{24 a}$ ), "Mal ganado es de guardar, mozas locas y 
En el siglo xvi se hacen más frecuentes las referencias. Inés Pereira "laurando canta: Quem bem tem e mal escolhe / por mal que lhe venha nam sanoje", que recogen en su forma castellana todos los refraneros antiguos; se cantaba, en efecto, y su melodía está en la ensalada La Guerra de Mateo Flecha el Viejo ${ }^{7}$. Otro personaje de Gil Vicente, en la Serra da Estrela (Copilaçam, fol. $172 \mathrm{r}^{\circ}$ ), canta la versión portuguesa del refrán Cuando aqui nieva ¿qué hará (será) en la sierra? ( $\mathrm{V}_{5}^{8} \mathrm{r}^{0}, \mathrm{~N} 101 \mathrm{v}^{0}, \mathrm{C} 13^{2} b$ ), cantado hoy en Asturias ${ }^{8}$.

Una monja de mediados del siglo xvi escribe una "canción contrahecha en cosa de deuoción a una que dize Allá miran ojos a do quieren bien" ( $\left.\mathrm{H}_{120}, \mathrm{C} 4 \mathrm{oa}\right)^{9}$. Como proverbios hay que considerar también el que cita Hernán Núñez $\left(106 \mathrm{~V}^{\circ}\right)$ con el comentario "cantar es éste más que refrán": Quien quisiere mujer hermosa el sábado la escoja, que no el domingo en la boda (además en ML $123 \mathrm{v}^{\circ}$, Ou 273-274) y La que no baila de la boda se salga (N $\left.65 \mathrm{v}^{\circ}\right)$, del cual explica Mal Lara $\left(99 \mathrm{r}^{\circ}\right)$ que "una parte es de un cantar que se dice en las bodas".

Si ignoramos la melodía de estos refranes, conocemos, en cambio, la de Las mañanas de abril dulces eran de dormir $\left(\mathrm{N}_{3} \mathrm{v}^{\circ}, \mathrm{Ou} \mathbf{1}_{60}\right.$; $\mathrm{CH}$ s.v. abril), recogida por Francisco Salinas en su gran tratado $D e$ musica libri septem (Salamanca, 1577), pp. $36_{3}, 39^{10}$. Por los mismos años el bachiller Arrieta cita en su polémico tratado sobre agricultura y ganadería muchos refranes referentes a bueyes y vacas, $y$ en seguida, separándolos expresamente de aquéllos, enumera varios cantares sobre el mismo tema; entre ellos: Las pascuas en domingo

por casar", $\mathrm{V}_{45} \mathrm{r}^{\mathrm{o}}$ (parecido en $\mathrm{N} 73 \mathrm{v}^{\mathrm{o}}, \mathrm{C} 287 a$; invertido en C $319 a$; fue también estribillo de poesía, como puede verse en este fascículo de la NRFH, p. 10o, núm. 134). El texto del Cancionero de la Colombina, con sus estrofas de tipo plenamente tradicional, tiene visos de canción antigua y arraigada.

7 S 625, A $62 \mathrm{r}^{\circ}, \mathrm{V} 60 \mathrm{r}^{\mathrm{o}}, \mathrm{N} 110 \mathrm{r}^{\mathrm{o}}, \mathrm{G} 66 \mathrm{r}^{\mathrm{o}}, 90 \mathrm{v}^{0}, \mathrm{M} 20$, Ou 271; Gil Vicente, Copilaçam de todalas obras..., Lixboa, $15^{62}$, fol. $218 \mathrm{v}^{\circ}$; M. Flecha, Las ensaladas, ed. H. Anglés, Barcelona, 1955, parte musical, p. 49. En un romance de fines de siglo, que comienza "Muchas cosas se me ofrecen / todas juntas a la par", leemos: “...le cantaba esta canción: / "Quien bien tiene y mal escoge..." ("Les romancerillos de la Bibliothèque Ambrosienne", ed. R. Foulché-Delbosc, $R H i, 45,1919$, pp. 510-624, núm. 99). El refrán-cantar aparece citado en muchos otros textos de la época.

8 Lo afirma, entre otros, E. M. Torner, $S, 43$ (1949), p. 3o2, núm. 160.

9 B.N.M., ms. 4257 , fol. $15 \mathrm{r}^{\circ}$ (cf. $R B A M, 4,1927$, p. 252). Confirma su carácter lírico-musical esta cita del Auto da Sioza de António Prestes (Primeira parte dos autos e comedias. . , Lisboa, $\left.1587,115 \mathrm{v}^{\circ}\right)$ : “Cantase là miram ojos / $\mathrm{e}$ eu canto a voltas disto / que de là me viram nojos"; sirvió también de estribillo a composiciones de Castillejo, Andrade Caminha y Diogo Bernardes.-Cf. infra, nota 17 .

10 Todavía se sigue cantando en España, a veces con el complemento “...y las de mayo sin fin ni cabo", que en forma análoga se conocía antiguamente (V $39 \mathrm{r}^{0} ; \mathrm{C}_{263} b$ ). Véase Torner, en $S$, 2 (1948), p. 88, núm. 98, y mis "Supervivencias de la antigua lírica popular", $H D A$, t. 1, p. 68. 
vende tus bueyes y compra trigo, que como refrán y con muchas variantes recogen Vallés, Núñez, Oudin y Correas ${ }^{11}$.

A comienzos del siglo xvn, en un romance del Romancero de Madrigal, se llama cantar al conocidísimo refrán $A l$ cabo de los (o A los) años mil vuelven las aguas por do solian ir ( $\mathrm{V}_{12} \mathrm{v}^{\circ}, \mathrm{N} 6 \mathrm{r}^{\circ}, \mathrm{C} 27$ a y $34 b)$; no nos atreveríamos a dar plena fe a este testimonio si no encontráramos el mismo refrán como canción en varias comedias de Lope de Vega ${ }^{12}$. Otras veces nos faltan esas corroboraciones. Sólo en una obra encuentro que se cantaba el refrán Que jurado lo tiene el baño de no hacer de lo negro blanco ${ }^{13}$. Sólo en el Viejo celoso de Cervantes he visto cantados -y aglutinados- los dos refranes El agua de por San Juan / quita vino y no da pan; /las riñas de por San Juan / todo el año paz nos dan (V $6 \mathrm{r}^{\circ}$, N $4 \mathrm{r}^{\circ}, \mathrm{Ou} 11, \mathrm{C} 15$ b; N 115 $\left.\mathrm{r}^{\circ}, \mathrm{G} 65 \mathrm{r}^{\circ}, \mathrm{C} 264 a\right)$. ¿Cómo saber, cuando no tenemos más que un único ejemplo, si esos refranes se cantaban comúnmente o se transformaban en canciones por la iniciativa personal y efímera de algún autor? No faltan testimonios tan sorprendentes como el de la Comedia Doleria (1572), donde leemos (NBAE, t. 14, p. $339 b)$ : “. . y cantará entonces la canción $D e$ tales polvos tales lodos": difícil concebir canción menos cantable.

En el folio $82 \mathrm{v}^{\circ}$ de la Philosophia vulgar figura este refrán: "Él anoche se murió, ella hoy casarse quiere: iguay de quien muere!” Al

11 Juan de [Valverdel Arrieta, Despertador que trata de la gran fertilidad, riquezas... que España solía tener... en la Agricultura general de Alonso de Herrera, Madrid, 1677, p. $346 a$ (quizá la primera edición suelta del tratado sea la de ${ }_{157} 8$, con aprobaciones de $157^{6}$, que cita Gallardo, Ensayo, t. 4, col. 892; en 1598 aparece "nuevamente añadido" a la Agricultura de Herrera, con la cual se imprimirá desde entonces).-Encuentro las siguientes versiones en los refraneros antiguos: "Cuando San Juan fuere en domingo, vende tus bueyes y échalos en trigo", V $64 \mathrm{v}^{\mathrm{0}}$; "Pascua en jueves vende tu capa y échala en bueyes", $\mathrm{N} 92 \mathrm{r}^{0}$ y C $386 a$; "Cuando corre Valfrío vende los bueyes y échalo en trigo", $\mathrm{N}$ ioo $\mathrm{r}^{\circ}$; "Navidad en viernes siembra por do pudieres; en domingo, vende los bueyes y échalo en trigo", $\mathrm{N} 80 \mathrm{v}^{\circ}$ (Ou 189, C 332b); "Navidad en domingo vende los bueyes y e. e. t.", C $332 a$; "Pascua en domingo vende tu capa y échalo e. t.", C $386 a$. Correas, p. $386 a$, dice expresamente: "tales refranes son propios de mozos de labranza".

12 Romancero general, ed. A. González Palencia, núm. 1144. Lope de Vega, Barlaán y Josafat, III, ed. J. F. Montesinos, Madrid, 1935, p. 147; Los Ponces de Barcelona, III, AcadN, t. 8, p. 592b; El hijo de los leones, 1, AcadN, 12, p. 273b; Con su pan se lo coma, III, AcadN, 4, p. 327; además auto El heredero del cielo, $\mathrm{Acad}$, t. 2, p. 182b. El refrán se cantó también en las fiestas con que se solemnizó el cuarto centenario de la ciudad de Valencia y se canta todavía -refundido en una cuarteta- en Andalucía (cf. Torner, S, 3, 1949, p. 286, núm. 143).

${ }_{13}$ Relación de las fiestas que la Universidad celebró desde 27 hasta $3 I$ de octubre $x 6 \mathrm{r8}$, Salamanca, 1618 (hay ejemplar en la H.S.A.), pp. 73-74. Sin el $Q$ ue inicial y con leves cambios de palabras figura en $\mathrm{S}_{375}, \mathrm{~V} 37 \mathrm{v}^{\mathrm{o}}$, G $88 \mathrm{r}^{\circ}$, C $254 b$. 
glosarlo observa Mal Lara: "Una manera de cantar hay que dice el vulgo:

Tres días ha que murió, la viuda casarse quiere. ¡Desdichado del que muere si a paraíso no va!"

Mal Lara distingue claramente entre la versión que se dice y la que se canta ${ }^{14}$. Es decir que el refrán, al convertirse en canción, se modifica. Y no necesariamente para adaptarse a un metro más lírico: acabamos de ver que se cantaban las cosas más inverosímiles, y entre los refranes-cantares aducidos hasta ahora hay varios que siguen un esquema poco frecuente en la lírica musical ("Niña y viña...", "Quien quisiere mujer hermosa...", "Al cabo de los años mil...").

Existen otros casos. El mismo Mal Lara $\left(245 \mathrm{r}^{\circ}-\mathrm{v}^{\circ}\right)$ registra como proverbio "Quien tiene hijo en tierra ajena, muerto lo tiene y vivo lo espera" (con variantes en V $63 \mathrm{v}^{\circ}, \mathrm{N} 111 \mathrm{r}^{\circ}, \mathrm{C} 421 a$ ), y como cantar (cf. NRFH, 12, 1958, p. 199):

Quien tiene hijo en tierra ajena muerto lo tiene y vivo lo espera, hasta que venga la triste nueva.

Una seguidilla del ms. 3915 de la B.N.M., fol. $318 \mathrm{v}^{\circ}$, dice:

$$
\begin{aligned}
& \text { Cuanto me mandareis } \\
& \text { todo lo haré: } \\
& \text { casa de dos puertas } \\
& \text { no la guardaré, }
\end{aligned}
$$

versión lírica del refrán "Todo te faré, mas casa con dos puertas no te guardaré” (S 698; cf. C $481 b$ ).

El refrán, en estos casos, ha sufrido una ampliación. Otras veces bastaba un ligero cambio. Así el proverbio "Por la puente se va a casa, que no por el agua" ( $\left.\mathrm{C}_{402} b\right)$ dio el cantar divulgadísimo en época de Lope ${ }^{15}$ :

${ }_{14}$ Otras fuentes contemporáneas parecen darle la razón. Horozco, $73^{6}$, cita la cuarteta Ilamándola cantar, y un pliego suelto la incluye entre otras poesías cantables (Chistes hechos por diuersos autores..., pl. s. gót., s.l.n.a., reimpreso por el Marqués de Jerez de los Caballeros, Sevilla, 189o, p. 19). Los refraneros ( $\left(3_{0} \mathrm{v} \mathrm{v}^{\circ}, \mathrm{N} 43 \mathrm{r}^{\circ}, \mathrm{C} 173^{a} ; \mathrm{M} 18\right)$ traen, con variantes, el texto que da Mal Lara como refrán ("Él anoche se murió..."), y no dicen que se cantara.

${ }_{15}$ "La letra que ahora se canta" dice en Por la puente, Juana, III, AcadN, t. 13 , p. 27oab; está en varios otros lugares; lo da también Correas, $402 b$, sin decir que sea cantar. No es imposible, desde luego, que ya existiera el refrán con Juana antes de aparecer la canción. 
Por la puente, Juana,

que no por el agua,

y esa misma Juana convirtió en canción otro refrán conocido, "Por (el) dinero baila el perro" ( $\mathrm{S} 542, \mathrm{~V} 55 \mathrm{v}^{\circ}, \mathrm{N} 96 \mathrm{v}^{\circ}$; cf. C $400 a b$ ):

-Por dinero baila el perro, Juana, por dinero baila.

-Salte y baile por dinero,

que yo por mi contento bailar quiero ${ }^{16}$.

En este último caso la canción rebasa en realidad los límites del proverbio. Ya no se trata propiamente de un "refrán cantado", sino de una canción en la cual entra un refrán. El procedimiento, muy frecuente en la lírica popular actual, se empleó también, pero menos, en la antigua: "Aunque soy morena, / no soy de olvidar, / que la tierra negra / pan blanco suele dar"17.

Con su lucidez habitual, Gonzalo Correas resume en una frase la relación entre el refranero y la poesía lírica musical: "De refranes se han fundado muchos cantares, y al contrario, de cantares han quedado muchos refranes"18. "D e cantares han quedado muchos refranes": es el otro aspecto de la cuestión.

Mucho antes de Correas, Juan de Mal Lara se había dado cuen-

${ }^{16}$ Cancionero musical de Turín, ed. G. M. Bertini, Poesie spagnole del Seicento, Torino, 1946, núm. 36. Al personalizarse, por medio de una interpelación, la sentencia abstracta parecía hacerse más apta para la expresión líricomusical. Así también, sobre el refrán "Debajo (so) el sayal hay ál" (N $122 \mathrm{r}^{\circ}$, $C_{151} a$ ) se construye el cantarcillo "Que debajo del sayal, Pascual, / que debajo del sayal hay ál", intercalado por Timoneda en su auto de La oveja perdida (Obras, Madrid, 1948, t. 2, p. 55). Y del refrán "Obras son amores, que no buenas razones" ( $V_{53} \mathrm{v}^{0}$, A $76 \mathrm{ro}^{\circ}, \mathrm{G} 64 \mathrm{v}^{\circ}$ y $95 \mathrm{r}^{\circ}, \mathrm{N} 88 \mathrm{v}^{\circ}$, Ou 227 , C $369 a$ ) debe de haber salido la copla "Obras son amores, / hermano Polo, / obras son amores, / que no amor solo" (baile Del amor y del interés, Flor de las comedias de España, $5^{\text {a }}$ parte, Barcelona, 1616 , fol. $26 \mathrm{v}^{\circ}$; C $\left.369 a\right)$, que con la variante “.. querida ingrata, ...que no palabras" aparece en el Laberinto amoroso y en la Segunda parte de la Primavera y flor de los mejores romances.

17 B.N.M., ms. 3915, fol. $320 \mathrm{v}^{\circ}$. Con un refrán mencionado supra, "Soy (ando) enamorado, / no diré de quién: / allá miran ojos / a do (donde) quieren bien", Poesias del siglo xvi, ms. de la H.S.A., fol. 184 [por error numerado 174] $\mathrm{r}^{\circ}$ (la descripción de este cancionero deberá publicarse en $N R F H, 16,1962$, núm. 1), y Cervantes, Baños de Argel, II, Comedias, ed. Schevill-Bonilla, t. 1, p. 290. Como se ve, el refrán va comúnmente al final del cantar, a veces con mención expresa: "Estos mis pollos de enero / mirá qué tales serán, / pues como dice el refrán / la pluma vale a dinero" (C $214 b$ ).

18 Arte de la lengua española castellana [1625], ed. E. Alarcos García, Madrid, 1954, p. 399 . 
ta del fenómeno. Al estudiar los refranes reunidos por el Comendador Hernán Núñez, observa que varios no son propiamente refranes. Duda un momento si adoptarlos o no, y luego se decide: "Yo no tengo por qué rehusar los refranes que puso, aunque algunos son cantarcillos" $\left(262 \mathrm{r}^{\circ}\right)$. Es verdad que en sentido estricto un cantar "no entra en cuenta de refrán" $\left(66 \mathrm{r}^{\circ}\right)$, pero también es cierto que "no pierde el refrán por ser cantar, porque se puede hacer el uno del otro" (123 v"). Al glosar el dístico "Plega a Dios que nazca / el perejil en el ascua", que Núñez $\left(95 \mathrm{~V}^{\circ}\right)$ había citado sin comentario alguno, el sevillano $\left(36 \mathrm{r}^{\circ}\right)$ anota escrupulosamente: "dícenme ser cantar viejo de Extremadura"; pero no importa, "que aunque éste sea cantar, parece haber sido bueno para refrán, pues el Comendador lo legitimó". Mal Lara acaba por convencerse a sí mismo a tal punto, que exclama $\left(66 \mathrm{r}^{0}\right)$ : "Si estos cantarcillos que todo el mundo los dice no son refrán, no sé qué será refrán".

Es evidente que Mal Lara usa aquí el término refrán en un sentido sumamente amplio y vago, cosa que no debe sorprendernos, puesto que todavía hoy se le suele tratar con análoga liberalidad. Un cantar o trozo de cantar que pasa a formar parte del habla familiar adquiere, sí, valor proverbial, pero no es un proverbio (a menos que por su contenido ya lo sea en sí mismo). Aceptemos la convincente caracterización que don Julio Casares ha dado del refrán: "Una frase completa e independiente, que en sentido directo o alegórico y por lo general en forma sentenciosa y elíptica, expresa un pensamiento -hecho de experiencia, enseñanza, admonición, etc.- a manera de juicio, en el que se relacionan por lo menos dos ideas", y que tiene un "contenido ideológico de interés general"19. Veremos que, aunque se cantaran, son refranes "La que no baila de la boda se salga" y todos los demás arriba citados. En cambio, "Plega a Dios que nazca el perejil en el ascua" no es refrán. Empleado en una conversación, este fragmento de cantar serviría de comentario irónico sobre una persona que espera la realización de algo imposible; el hablante recordaría a la muchacha cuya madre ha prometido casarla cuando ocurra ese prodigio y que ingenuamente expresa el deseo de que ocurra.

En su excelente deslinde entre el refrán y la frase proverbial muestra Casares que casi siempre "lo que se ha convertido en frase proverbial es un dicho o un texto que se $\mathrm{h}$ i $\mathrm{z}$ o famoso por el acontecimiento histórico que le dio origen.... por la anécdota, real o imaginaria, a que se refiere", etc. (op. cit., p. 189); "su uso en la lengua tiene el carácter de una cita, de una recordación, de algo que se trae a cuento ante una situación que en algún modo se asemeja a la que dio origen al dicho" (p. 19o). Aunque Casares no los mencione expresamente, los cantares proverbializados entran en esa categoría. Suelen tener sobre otras frases proverbiales la ven-

19 Introducción a la lexicografía moderna, Madrid, 1950, pp. 192 y 196. 
taja de estar configurados en un esquema métrico análogo al de muchos refranes.

La amplitud de criterio de que dan fe las palabras de Mal Lara es común a todos los refraneros antiguos (para no hablar de los modernos). Entre los proverbios propiamente dichos insertan locuciones de muchas clases, cantares y hasta pregones, adivinanzas, rimas infantiles ${ }^{20}$. Ya en la pequeña recopilación atribuida a Santillana hay por lo menos dos canciones: Campanillas de Toledo, / óigovos y no vos veo (S 176; además V $17 \mathrm{~V}^{\circ}, \mathrm{H}_{519}, \mathrm{C}{ }_{103} b$ ) y Por más que me digades, / mi marido es el pastor $\left(\mathrm{S}_{5} 63 \mathrm{y} \mathrm{V} 57 \mathrm{r}^{\circ}, \mathrm{N}_{96} \mathrm{r}^{\circ}\right.$, ML $98 \mathrm{v}^{0}$ y $\left.115 \mathrm{v}^{0}, \mathrm{C}_{403} a\right)^{21}$. Pedro Vallés da, además de estas dos, varias otras, como: Con las bajas no curé, / las altas de mi tampoco; / con estas temas de loco / todo mi tiempo gasté (V $18 \mathrm{r}^{\circ}$ y ML $66 \mathrm{r}^{\circ}$ ) o -Comadre la mi comadre, / al coladero sabe. / -A la fe, de vero, / que sabe al coladero ( $\mathrm{V}_{1} 8 \mathrm{v}^{\circ}$ y $\mathrm{N}_{25} \mathrm{v}^{\circ}$, ML $262 \mathrm{r}^{\circ}, \mathrm{C}_{11} 5^{b}$ ); de ambas dice Mal Lara expresamente que son cantares.

Pocos años después de la colección de Vallés se publica el riquísimo refranero de Hernán Núñez, rico también en cantares y fragmentos de cantares. Al citar $\left(92 \mathrm{v}^{\circ}\right)$

Para la muerte que a Dios debo, de perejil está el mortero,

comenta Núñez: "Dicen las mozas que es cantar", y da su continuación:

Comadres, las mis comadres,
yo tengo dos criadas
muy bellacas y muy malas:
por estarse arrellanadas
nunca limpian el majadero.

(Según Correas, $3^{8} 3^{a}$, se aplica a "los que se espantan y hacen caramillo de cosas de nonada"). El Comendador incluye muchos otros cantares sin decir que lo son. En el Cancionero musical de Palacio, anterior en medio siglo a la recopilación de Núñez, están con música Allá se me ponga el sol / do(nde) tengo el amor ( $\mathrm{N}_{9} \mathrm{r}^{\circ}$ y $\mathrm{Ou} 28, \mathrm{C}$ 4oa), Cucú, / guarda no lo seas tú ( $28 \mathrm{v}^{\circ}$ y ML $\left.78 \mathrm{v}^{\circ}, \mathrm{C} 143 a\right)$,

20 Pregones como "Santisteban de Gormaz, cedaz, cedaz" (V 67 ro, C 445b), adivinanzas como "Cient dueñas en un corral todas dicen un cantar" (=las ovejas; N $25 \mathrm{r}^{\circ}, \mathbf{C}_{113}$ ), rimas infantiles como "Arca, arquita, / de Dios bendita, / cierra bien y abre, / no te engañe nadie" ( $\mathrm{N}_{14} \mathrm{r}^{\circ}, \mathrm{ML} 7 \mathrm{v}^{\circ}$ ) y muchas otras.

$21 \mathrm{La}$ música del primero está, con letra contrahecha, en la ensalada $L a$ viuda de Mateo Flecha (Las ensaladas, Baxo, Praga, 1581, fol. $21 \mathrm{r}^{0}-\mathrm{v}^{0}$ ). Del segundo sabemos que era canción gracias a varios pliegos sueltos del xvi: contienen un villancico que debia cantarse "al tono de «Por más que me digáis, mi marido es el pastor" (cf. mis "Supervivencias...", art. cit., p. 64). 
Perdi la mi rueca / y el huso non fallo. / ¿isi vistes allá / [e]l tortero andar?22. Luis de Narváez conserva en su Delphin de música (ed. E. Pujol, Barcelona, 1945, núms. 37-39) una melodía del famoso cantar Si tantos monteros (halcones) / la garza combaten, / ipor Dios que la maten! ( $\mathrm{N} 119 \mathrm{v}^{\circ}$ y $\mathrm{M} 28, \mathrm{C}_{4} 61 b, \mathrm{CH}$ s.v. garça), y en una ensalada musical figura la de Yo solo / ¿cómo lo haré todo? $\left(\mathrm{N} 130 \mathrm{v}^{\circ}\right.$ y C $5^{16 b}$; cf. NRFH, 12, 1958, p. 325). De otros textos nos consta que eran canciones, aunque no se conserve la música; otros muchos lo parecen, sin que hayamos podido comprobar que lo fueran.

Si hemos de creer a Mal Lara, el Comendador insertó todos esos cantarcillos en virtud de su valor proverbial. Lo que no queda nada claro es si ese valor era real o potencial: si los cantares ya se citaban corrientemente en el lenguaje hablado o si el humanista coleccionador de refranes los aducía por creer que se les podía extraer una sustancia ejemplar ("se puede hacer el uno del otro", "parece haber sido bueno para refrán", "el Comendador lo legitimó”... ).

Interesantes son a este respecto los comentarios que Gonzalo Correas -mucho más "folklorista" que sus antecesores- hace a algunos de los textos recogidos en su monumental Vocabulario de refranes y frases proverbiales y otras fórmulas comunes de la lengua castellana; dice, por ejemplo: "refrán que salió de cantar", "de cantar viene a ser refrán", "tómase de un cantar" o simplemente "fue cantar"23. Podemos tomarle la palabra: aquellas canciones habían pasado al repertorio proverbial español. Por otra parte, Correas recogió, sin comentario alguno, centenares de canciones de las cuales no sabemos en absoluto si estaban proverbializadas o $\mathrm{no}^{24}$.

22 Cancionero musical de Palacio, ed. H. Anglés, Barcelona, 1947-1951, núms. 431, 94 y 101, 253. Del tercer texto da Núñez una versión invertida: “¿Si vistes allá el tortero andando, que perdí la rueca y el huso no hallo?" $\left(121 \mathrm{v}^{\circ}\right)$, y además "Perdí la rueca y el huso no hallo: tres días ha que le ando en el rastro" (94 vo), "A buscar la ando la mala de la rueca y no la hallo" ( $1 \mathrm{v}^{0}$; también en Ou 3-4, quien traduce "le la vay chercher celle qui est malade de la quenoüille [?]..."). Correas copió de Núñez estos tres textos $(462 b, 390 a$ y $7 a)$ y añadió otras versiones $(390 a, 94 b)$.

23 El primer comentario (284b) se refiere al famoso "Madre, la mi madre, / guardas me ponéis..." (cf. D. Alonso y J. M. Blecua, Antología de la poesia española. Poesía de tipo tradicional, Madrid, 1956, núm. 418; en adelante abreviaré Antol.); el segundo $(211 b)$ a "Estábame yo en mi estudio / estudiando la lición..." (Antol., 299); el tercero (213a) a "Este abad que aquí tenemos / cómo le pelaremos?"; el último a varios, por ejemplo, "Mira bien y ten acuerdo, / que te toques por enmedio" $(314 b)$. Creo que cuando Correas usa la palabra cantar no hay duda de que lo era en efecto. En cambio, Mal Lara parece haberle dado alguna vez un sentido figurado; dice por ejemplo $\left(103 \mathrm{v}^{\circ}\right)$ que "La doncella no la llaman y viénese ella" (N $\left.67 \mathrm{r}^{\circ}\right)$ "cantar es para las mozas que están en edad de toda guarda", o que "Amárgame el agua, marido, amárgame y sabe a vino" es "como una cancioncilla reprehendiendo" (253 vo).

24 Nos consta que algunas son canciones porque están documentadas como tales en otras obras antiguas o porque sobreviven en la tradición oral (cf. "Su- 
Por fortuna, no son las colecciones de refranes la única fuente para documentar la proverbialización de cantares en el Siglo de Oro. La literatura de la época nos ofrece abundantes testimonios. En su Romancero hispánico (xv, 8) Menéndez Pidal ha estudiado el uso de "Versos del romancero como elementos fraseológicos del lenguaje" y concluido que "toda la literatura española de los siglos áureos aparece sembrada de brotes romancescos". Lo mismo puede decirse de la poesía lírica de tipo popular o semi-popular. En los más diversos géneros -teatro, novela, crónicas, cartas, hasta poesía lírica- salta el recuerdo de canciones tradicionales o de moda, evidentemente ya convertidas o a punto de convertirse en "elementos fraseológicos del lenguaje".

Alguna vez el autor hace la advertencia de que está citando una canción: "Si Gerarda ha descubierto esta yerba, que las tales llaman mandrágora, y la tiene Dorotea, ¿qué espectáculo, qué música, qué vino como ella misma, para que descanse mi amado preso, c o mo dice la letrilla que agora cant a n?" (Lope, Dorotea, III, 4; ed. E. S. Morby, p. 247); "E eu por mi digo co m a $\mathrm{c}$ a $\mathrm{t}$ ig a Si lo dizen digan ec... (Ferreira de Vasconcellos, Eufrosina, prólogo; ed. E. Asensio, p. 3). Pero casi siempre la cita, repentina y desnuda, es como un guiño al lector o al público: “...pois por vida de mis ojos, caualhero, que quando acertam de nos cayr nos olhos algũs rayos..." (António Prestes, Representaçam que precede al Auto dos dous hirmãos, en Primeira parte..., op. cit., fol. $75 \mathrm{r}^{\circ}$ ); "[Alma]-...mil golpes de contrición / daré en las puertas erradas. / Iglesia-Y todas tus aldabadas / darán en mi corazón" (Valdivielso, auto Las ferias del alma, Doze actos...., Toledo, 1622, fol. 9o $\mathrm{r}^{\circ}$ ); “Ay, qué miel tan sabrosa! ¡No lo pensé! ¡Aguza, aguza, dale si le das, que me llaman en casa!. . " (F. Delicado, Lozana andaluza, xIv; ed. A. Vilanova, p. 53); “... y si acaso yo al descuido les daba una onza de mirame Miguel..." (Pícara Justina, IV, 3; ed. Puyol, t. 2, p. 275); "Preguntai-lhe de do viene; veréis que algo tiene en el campo que le duele" (Camoens, Carta I, versión de la Miscelánea Juromenha; $Z R P h, 7,1889$, p. 447); "Si quieres que no te quiera, / me digas tu vida, Inés, / que si es posible olvidarte, / yo te lo diré después" (romance de Antonio Hurtado de Mendoza, Obras poéticas, Madrid,

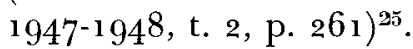

pervivencias. ..", art. cit., núms. $15,25,36,40,49,50,53,54,5^{6}, 59$ y 61 ). Otras muchas tienen aire de cantares, pero, como en el caso de Núnez, nos faltan las pruebas.

${ }^{25}$ Las citas corresponden a los siguientes cantares: "Galeritas de España, / parad los remos, / para que descanse / mi amado preso" (entre otras fuentes, en Romancero general, ed. cit., núm. 887); "Si lo dicen, digan, / alma mía, / si lo dicen, digan" (Antol., 36); "Por vida de mis ojos, / el caballero, / por vida de mis ojos, / bien os quiero" (Antol., 129 y 384 ); "Llaman a la puerta, / espero yo a mi amor, / y todas las aldabadas / me dan en el corazón" (asi en el auto 
Para el investigador de la antigua lírica estos testimonios son preciosos, pues revelan la divulgación de cantares a veces muy escasamente documentados. Claro que esa divulgación podía en ocasiones limitarse a cierta región de España o aun a un círculo reducido; así sabemos, por ejemplo, que en la corte valenciana de doña Germana de Foix se recordaba a cada paso la canción "No me sirváis, caballero, / íos con Dios, / que no me parió mi madre / para vos" ${ }^{26}$, y si hemos de creer a los autores portugueses del xvi, muy dados a citar cantares populares en sus obras, en Portugal se traía a cuento aquello de "Afuera, fuera, fuera, / el pastorcico, / afuera has de dormir, / que no comigo. .."27 cada vez que quería rechazarse a alguien. Otros muchos cantares lograron, en cambio, una amplia y a veces duradera proverbialización, como veremos en algunos ejemplos.

Lo común era citar sólo uno o dos versos. Del famosísimo cantar de "La bella malmaridada" - su fama misma era proverbial- se desgajó el segundo verso, de las más lindas que vi, incontables veces recordado en los siglos xvi y $\mathrm{xvn}^{28}$. Todavía el Diccionario de la

El Fénix de amor del propio Valdivielso, Doze actos, fol. $39 \mathrm{v}^{\circ}$; con ligeras variantes en otras fuentes); "Dale si le das, / mozuela de Carasa, / dale si le das, / que me llaman en casa" (Canc. musical de Palacio, ed. cit., núm. 141); "Pues que me tienes, / Miguel, por esposa, / mírame, Miguel, / cómo estoy tan hermosa" (C $412 b$ et al.; cf. Antol., 304); "Aquel partorcico, madre, / que no viene, / algo tiene en el campo / que le duele" (Antol,, 64; cf. "Estar triste Dorotea y no ir a los toros..., algo tiene en el campo que le duele", Lope, Dorotea, V, 2, ed. Morby, p. 386); "Un poco te quiero, Inés: / yo te lo diré después" (C 4966; Lasso de la Vega, Manojuelo de romances, Madrid, 1942, núm. 92).

26 Está en un pl. s. gótico reimpreso en Cancionerillos góticos castellanos..., ed. A. Rodríguez-Moñino, Valencia, 1954, pp. 67-7o. Se cita tres veces en el Cortesano de Luis Milán, siempre con el final cambiado: “. .que quien hace malas coplas / nescio vos", "que pelliscada voy por vos", "que purgada estoy por vos" (ed. Valencia, $1^{6}$, fols. [21] vo, [165] ro y [233] vo; ed. Madrid, 1874 , pp. 53,335 y 464$)$.

${ }_{27}$ Asi en un pl. s. de Praga (RHi, 61, 1924, p. 166). Timoneda, Sarao de amor, fol. 54 ro, trae ". . que nel campo dormirás / y no comigo". Citan el cantar: Camoens, Carta I (Obras completas, ed. H. Cidade, t. 3, p. 230): "e mande escumar o entendimento, que de outra manera de fuera dormiredes, pastorcico" (cf. Enfatriões, ibid., pp. 60, 61 y 71, y "Disparates da India"); Jorge Pinto, Auto de Rodrigo e Mendo (Primeira parte..., op. cit., fol. 50 vo): "Afuera, pastorsico... que nel campo dormirás, que não comigo"; António Prestes, Auto do Procurador (ibid., fol. $26 \mathrm{v}^{0}$ ): "-Eyla vem dessemulemos, / que nel campo dormirás... / -Que não comigo" (cf. su Auto da Ave Maria, ibid., fol. 6 r $^{\circ}$ ). En el último ejemplo la cita se canta. Esto no es raro. Recuérdese que cuando los soldados de Gonzalo Pizarro empiezan a pasarse al bando contrario, "un maestre de campo suyo, llamado Carvajal, cantaba "Estos mis cabellos, madre, / dos a dos se los lleva el aire»" (Oviedo, Historia general..., IX, 11 ; repiten la anécdota el Inca, Gutiérrez de Santa Clara, el Palentino, Gómara, la Miscelánea de Zapata). Aun cantada, el recuerdo de la canción tiene carácter plenamente proverbial.

28 Unos cuantos ejemplos: Gil Vicente, Copilaçam, fol. $244 \mathbf{v}^{0}$, "que este galán desposado, / de los más lindos que yo vi"; Pedro de Padilla, Thesoro, 
Academia registra, s.v. doblar, la locución bien pueden doblar por él (C $84 b$ ), que muy probablemente procede del cantar rufianesco “QQuién te me enojó, Isabel, / que con lágrimas te tiene? / Yo hago voto solene / que pueden doblar por él" (Salinas, De musica, p. 356); con sus dos últimos versos solía caracterizarse al arrogante y bravucón, del cual se decía también que era "de los de «Quién te me enojó, Isabel»"29. Análogamente se decía que una mu jer fogueada que afectaba inocencia era "de aquellas de nunca en tal me vi" (Estebanillo González, viII; ed. Millé y Giménez, Madrid, 1934, t. 2, p. 87), por la bien conocida canción "Señor Gómez Arias, / doléos de mí, /soy mochacha y niña / y nunca en tal me vi"30.

Una de las canciones más citadas, imitadas y parodiadas del siglo xviI -y por ende de las más proverbializadas- es "Aprended, flores, de mí, / lo que va de ayer a hoy, / que ayer maravilla fui / y hoy sombra mía aun no soy", que se ha atribuido a Góngora, y bien pudiera ser de él. Su recuerdo venía a la memoria cuantas veces se pensaba en la vanidad de las cosas terrestres. Se la citaba entera o, más frecuentemente, por sus dos primeros versos, a menudo contrahechos; su fama se ha perpetuado hasta nuestros días ${ }^{31}$. Un caso análogo

Madrid, 1580 , fol. 345 vo, "A la más linda señora, / de las más lindas que vi"; Lope de Vega, Lo que pasa en una tarde, III, $A$ cadN, t. 2, p. 320b, "-¿Qué es esto, esposa? -Un mal fiero... / de los más lindos que vi".

${ }^{29}$ C $574 b$ (los editores imprimen erróneamente "Quien tomó enojo, Isabel"). Cf. Picara Justina, ed. J. Puyol, t. 1, p. 77 y t. 3, pp. 267-269 (donde Puyol reúne muchas citas).

30 El verso final aparece ya con ese sentido proverbial en la Lozana andaluza; después en Ferreira de Vasconcellos, en el Crotalón, en la Picara Justina. Véase la edición de Puyol citada en la nota anterior, t. 3, p. 280, y ahora $L a$ niña de Gómez Arias de L. Vélez de Guevara, ed. R. Rozzell, Granada, 1959, pp. 26 ss.

31 Cf. L. Medina, "Frases literarias afortunadas", $R H i, 25$ (1911), pp. 52 y 54-55, y Hannah E. Bergman, "El Romancero en Quiñones de Benavente", en este mismo número de la $N R F H$, p. 238 y nota 24 . A los datos reunidos en ambos trabajos añadiré algunos más. Lope también glosó el cantar en $E l$ desprecio agradecido, II, AcadN, t. 12, p. I6ab. Otras glosas: Estebanillo González, 13 (BAE, t. 33, p. $367 b$ ); B.N.M., mss. $405^{1}$ y 17,669 , fols. 504 ro y 97 ro respectivamente. Los dos primeros versos suelen citarse -intactos o cambiados- al final de una cuarteta, cuyos dos primeros versos expresan la antítesis "ayer. . hoy". Por ejemplo, la comedia burlesca del Hermano de su hermana de Quirós (Obras, Madrid, 1656, fol. $121 \mathrm{r}^{\circ}$ ): "Ayer morí y hoy no soy / don Sancho como lo fui: / aprended, flores..."; Cáncer, baile de La fábula de Orfeo (Autos sacramentales..., Madrid, 1675, pp. 210-211): "Hoy sin Eurídice estoy / y ayer con ella me vi: / aprended, flores..."; María de Zayas, romance a la muerte de Pérez de Montalván ( $B A E$, t. 42 , p. 548a): "Ayer fui, ya no soy nada, / la muerte de mí triunfó: / aprended, hombres, de mí...". Flores aparece sustituido por damas en Casa con dos puertas de Calderón, III, 3 ( $B A E$, t. 7 , p. 142b; cita sólo los dos primeros versos); por asnos en el entremés Lo que pasa en una venta de Belmonte (Flor de entremeses [1657], Madrid, 1903, p. 173): "Aprended, asnos, de mí, / lo que va de ayer a hoy: / que ayer desechado fui, / y hoy apetecido soy". Hay dos contrahechuras más piadosas en el Ramillete de Jacinto de Evia, Ma- 
es el de "Soñaba yo que tenía / alegre mi corazón, / mas a la fe, madre mía, / que los sueños sueños son". Su último verso, muchas veces citado, pudo ser proverbial independientemente de la cuarteta, pero ésta misma aparece proverbializada a menudo, sobre todo en obras de teatro: ante el desastre económico del "autor" Antonio de Prado, en la Loa que le dedicó Quiñones de Benavente (NBAE, t. 18 , p. $5^{16} 6$ ), cantan los músicos "Soñó el autor que tenía / un bolsón y otro bolsón; / mas a la fe, compañía, / que los sueños sueños son"; y León Marchante pudo decir en su Picaresca (carta 67): “. . . acordándome de aquel adagio de los siete durmientes que dice pero a la fe, prima mia, que los sueños sueños son..."32.

Alguna vez ocurre que no se proverbializa el cantar mismo, sino el hecho de cantarlo. Es el caso de "Las tres ánades, madre, / solas van por aquí; / malpenan a mí" (C 105a), pues, como apunta Covarrubias en su Tesoro (s.v. ánade), "para decir que uno va caminando alegremente, sin que sienta el trabajo, decimos que va cantando tres ánades, madre". "Y cantando las tres ánades, madre, / dejé a mi hermano y a mi propio padre", leemos en el Siglo pitagórico de Enríquez Gómez (ed. Roan, 1644, p. 169) ${ }^{33}$.

¿Por qué precisamente "las tres ánades, madre"? Hoy resulta difícil comprenderlo. Y otra cosa incomprensible: que no parezcan haberse proverbializado una serie de cantares de contenido sentencioso. Esperaríamos encontrar en los refraneros de la época -y no encontramos- cantares como "Más trabaja que el que cava / el que tiene la mujer brava" (Lope de Rueda, Coloquio de Camila, Obras, Madrid, 1908, t. 2, p. 46), o "Quien amores ten / afinque-los ben, / que nan é veinto que va y ven” (L. Milán, El maestro, Valencia, ${ }_{1536}$, fol. $\left.41 \mathrm{r}^{0}-\mathrm{v}^{\circ}\right)$, o "Quien de sus amores se aleja / no los hallará como los deja” (Horozco, Cancionero, Sevilla, 1874, p. 27).

Éstos que podríamos llamar "cantares arrefranados" o "refranes-

drid, 1675 , pp. 22 y 37 -Sobre la divulgación del cantar desde el siglo xvir, cf. Torner, $S$, 1, núm. 2, pp. 5-6. García Pérez menciona en su Catálogo, p. 479, una glosa de Juan Brito y Luna (1721), y Serrano y SANz, en sus Apuntes para una biblioteca de escritoras españolas...., Madrid, 1903, t. 1, p. 519, una imitación de Margarita Hickey y Pellizzoni (muerta después de 1791): "Aprended, Clicies, de mí, / lo que va de ayer a hoy: / de amor extremo ayer fui, / leve afecto hoy aun no soy". En nuestro siglo ha citado y comentado la cuarteta el colombiano Antonio José Restrepo, creyéndola nacida "de lo hondo del pueblo antioqueño" (cf. la revista Bolivar, 1955 , núm. 42, p. 322).

32 Citado en Anales salmantinos, 2 (1929), p. 332. Sobre la Loa que representó Antonio de Prado (incluida también entre las Obras varias de Cáncer, Madrid, 1651), cf. ahora H. E. Bergman, en este número, p. 230 y passim. F. G. OLMEDo reproduce en Las fuentes de "La vida es sueño" algunas glosas de la copla, a las cuales podrían añadirse muchas más. Cf. también J. F. Montesinos, ed. de Lope de Vega, Barlaán y Josafat, p. 248, nota 1.

33 Hay otras muchas citas, varias de ellas recogidas por Daniel Devoto en su Cancionero llamado Flor de la rosa, Buenos Aires, 1950, pp. 137-1 38 . 
eos" viven también en el territorio que nos hemos propuesto explorar. ¿Serían originalmente refranes, que después, al ser puestos en música, abandonaron el campo del refranero por el de la lírica? Nos asalta la misma duda que ya plantean en realidad los refranes cantados, duda más ardua de resolver que la de la gallina o el huevo: en cada caso ¿qué fue antes, el refrán o el cantar? Si son tantos los refranes con "aire de canción" y los que eran indudablemente canciones, y si, por otra parte, hay buen número de cantares que parecen refranes, lo más justo será quizá renunciar a establecer prioridades. Es evidente que desde la remota Edad Media existió una base para el intercambio constante entre cantares y refranes, tanto más cuanto que éstos adoptaban a menudo un esquema - dísticos rimados- frecuente en la lírica popular, la cual, por su parte, se caracterizaba por una gran flexibilidad métrica y aun temática y podía acoger sin dificultad textos breves de forma irregular. Así se llegó probablemente a una especie de indiferenciación: el proverbio era verso y el verso refrán.

Reliquia de este estado de cosas serían todos esos refranes-cantares documentados en los siglos XV-Xvir, algunos de los cuales subsisten en el folklore hispánico de nuestros días. Al correr el tiempo se produciría una mayor separación entre ambos géneros, sin que jamás se perdiera el contacto entre ellos. Con el auge y monopolio de la copla y la seguidilla se acentuaría esa diferenciación formal manifiesta ya, como vimos, en los cantares antiguos que eran refranes ampliados; a la vez, dado el carácter predominantemente sentencioso de la nueva poesía popular, aumentaría en mucho el número de cantares que incorporan un refrán ${ }^{34}$. Valdrá la pena estudiar todo esto y completar así el fragmentario e imperfecto panorama esbozado en estas páginas.

Margit Frenk Alatorre

El Colegio de México.

\footnotetext{
34 En sus cuatro tomos de refranes aduce Rodríguez Marín bastantes cantares que son proverbios convertidos por ampliación o reducción en copla o en seguidilla; por ejemplo: "No hay luna como la de enero, ni amor como el primero" se ha hecho "No hay lunita más clara / que la de enero, / ni amores más queridos / que los primeros" (Mas de 2 , ooo refranes castellanos, Madrid, $\left.1926, p .335^{b}\right)$. Y cita asimismo coplas que utilizan un refrán sin cambiarlo: "Entre dos que bien se quieren, / con uno que coma basta, / y éste ha de ser la mujer, / por ser la parte más flaca" (ibid., p. 195b).
} 